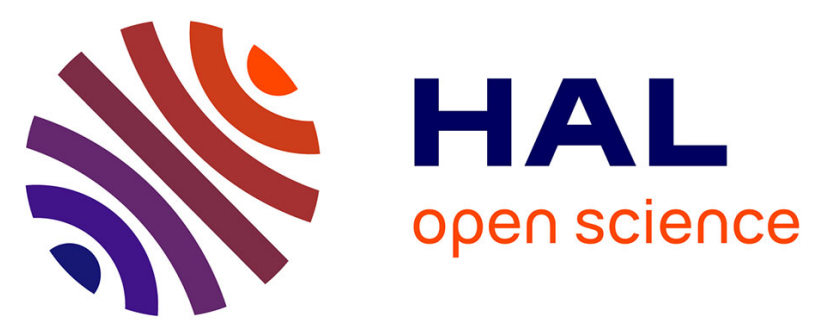

\title{
Mechanostereoselective One-Pot Synthesis of Functionalized Head-to-Head Cyclodextrin [3]Rotaxanes and Their Application as Magnetic Resonance Imaging Contrast Agents
}

Jean Wilfried Fredy, Jérémy Scelle, Gregory Ramniceanu, Bich-Thuy Doan, Célia S. Bonnet, Éva Tóth, Mickaël Ménand, Matthieu Sollogoub, Guillaume Vives, Bernold Hasenknopf

\section{- To cite this version:}

Jean Wilfried Fredy, Jérémy Scelle, Gregory Ramniceanu, Bich-Thuy Doan, Célia S. Bonnet, et al.. Mechanostereoselective One-Pot Synthesis of Functionalized Head-to-Head Cyclodextrin [3]Rotaxanes and Their Application as Magnetic Resonance Imaging Contrast Agents. Organic Letters, 2017, 19 (5), pp.1136-1139. 10.1021/acs.orglett.7b00153 . hal-01480341

\section{HAL Id: hal-01480341 \\ https: / hal.sorbonne-universite.fr/hal-01480341}

Submitted on 1 Mar 2017

HAL is a multi-disciplinary open access archive for the deposit and dissemination of scientific research documents, whether they are published or not. The documents may come from teaching and research institutions in France or abroad, or from public or private research centers.
L'archive ouverte pluridisciplinaire HAL, est destinée au dépôt et à la diffusion de documents scientifiques de niveau recherche, publiés ou non, émanant des établissements d'enseignement et de recherche français ou étrangers, des laboratoires publics ou privés. 


\title{
Mechanostereoselective one-pot synthesis of functionalized head- to-head cyclodextrin [3] rotaxanes and their application as Magnetic Resonance Imaging contrast agents
}

\author{
Jean Wilfried Fredy, ${ }^{\dagger \S}$ Jérémy Scelle ${ }^{\dagger \S}$ Gregory Ramniceanu, ${ }^{\ddagger}$ Bich-Thuy Doan, ${ }^{\dagger}$ Célia S. Bonnet, ${ }^{\Uparrow}$ Éva \\ Tóth, ${ }^{\Uparrow}$ Mickaël Ménand, ${ }^{\dagger}$ Matthieu Sollogoub,${ }^{\dagger}$ Guillaume Vives, ${ }^{\dagger *}$ Bernold Hasenknopf ${ }^{\dagger *}$ \\ † Sorbonne Universités, UPMC Univ Paris 06, CNRS, Institut Parisien de Chimie Moléculaire UMR 8232, 4 place Jussieu, \\ 75005 Paris (France) \\ *Chimie ParisTech, CNRS, UMR8258 INSERM U1022 Unité de Technologies Chimiques et Biologiques pour la Santé, 11 \\ rue Pierre \& Marie Curie, 75005 Paris, (France) \\ " Centre de Biophysique Moléculaire, CNRS UPR4301, Université d’Orléans, Rue Charles Sadron, 45071 Orléans Cedex2 \\ (France)
}

Supporting Information Placeholder
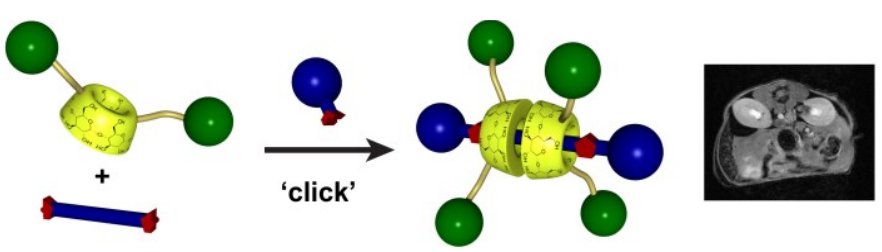

\begin{abstract}
A versatile five-component one-pot synthesis of cyclodextrin (CD) [3]rotaxanes using Copper-catalyzed Azide-Alkyne Cycloaddition (CuAAC) has been developed. Head-to-head [3]rotaxanes of $\alpha$-CD selectively functionalized by one or two gadolinium 1,4,7,10-tetraazacyclododecane-1,4,7-triacetic acid monoamide (Gd-DO3A-MA) complexes were obtained mechanostereoselectively. The Magnetic Resonance Imaging (MRI) efficiency, expressed by the longitudinal proton relaxivity of the rotaxanes was significantly improved as compared to the functionalized CD. In vitro and in vivo preclinical studies showed a higher contrast and retention in the kidney than gadolinium 1,4,7,10-tetraazacyclododecane1,4,7,10-tetraacetic acid complex (Gd-DOTA) demonstrating the potential of these rotaxanes as MRI contrast agent.
\end{abstract}

Supramolecular chemistry offers modularity and fast synthesis of complex molecular objects. It is therefore well adapted to biological applications where multifunctional and modular devices are needed. Furthermore, in view of in vivo applications and eventual approval by regulatory agencies, the obtention of a single molecular species is preferable. We are particularly interested in the development of multimodal imaging agents using such a modular supramolecular approach. Our concept consists of preparing monofunctional molecular building units that self-assemble in a modular fashion to produce multifunctional imaging agents. A particularly appealing architecture for this are polyrotaxanes composed of different rings threaded on a common axle. ${ }^{1}$ However, efficient threading of functionalized rings must be guaranteed, and different mechano-isomers, i.e. diastereomers that differ in the orientation of the mechanically bonded rings, ${ }^{2}$ can be obtained using this strategy.

While a large variety of macrocycles such as cucurbituril, crown-ether, bis-paraquat or calixarene have been reported to produce rotaxanes, ${ }^{2-3}$ cyclodextrins (CDs) present the particular advantages to be commercially available, cheap and easily functionalizable. ${ }^{4}$ Moreover, CDs are biocompatible and water-soluble which enables the access to hydrosoluble rotaxanes with potential applications in biology and medicine such as imaging. ${ }^{1,5}$ Native CDs have been widely used in rotaxanes or polyrotaxanes, ${ }^{6}$ since the synthesis of first CD [2] rotaxane described by Ogino. ${ }^{7}$ They are usually obtained by threading followed by end-capping reaction, with the hydrophobic effect as driving force for the self-assembly process. This requires forming the pseudo-rotaxane in water and, after isolation or in situ, performing the stoppering reaction also in aqueous solution to prevent the dethreading. These limitations have resulted in i) few $C D$ rotaxanes described in the literature contain two CDs, and ii) polyrotaxanes assembled with already functionalized CDs remain less explored and form a mixture of orientational mechanoisomers. $^{8}$

Based on the polyammonium-CD polyrotaxanes described by Wenz, ${ }^{6 a, 9}$ we have developed polyrotaxanes with Gdfunctionalized $\mathrm{CDs}^{1}$ that showed improved relaxivities compared to small molecules. It was also possible to thread bodipy and Gd-functionalized CDs simultaneously onto the polymer strand, proving the viability of the approach to obtain bimodal agents (fluorescence and MRI). However, they were obtained as a statistical mixture of orientational mechanoisomers and their high toxicity prevented their use in vivo.

In order to lower their toxicity, to test different functionalized CDs, to get single isomeric compounds, and to better understand the intrinsic role of the rotaxane architecture on the 
MRI properties, we decided to investigate smaller [3] rotaxanes as models for the above mentioned polyrotaxanes. While various synthetic strategies have been developed for multiple threading of other macrocycles ${ }^{10}$, in particular the 'activemetal template strategy', ${ }^{11}$ only few methods yielding [3] rotaxanes of CDs have been described. Anderson showed that reaction of 2,6-dimethylphenol with bis-diazonioazobenzene in the presence of $\alpha-C D$ gave a tail-to tail [3] rotaxane. ${ }^{12}$ Takata has recently reported another one-pot strategy to directly obtain head-to-head [3] rotaxanes of $\alpha-C D$ by using isocyanate stoppers. ${ }^{13}$ A solid-phase synthesis yielded a head-to-tail [3] rotaxane, ${ }^{14}$ and the coupling of two pseudo-[2]rotaxane gave a tail-to-tail [3]rotaxane. ${ }^{15}$ Fort prepared polyrotaxanes with lactose-functionalized $\alpha-C D .{ }^{8 c}$ Inspired by these results and the use of click chemistry for the stoppering reaction of CD-rotaxanes, ${ }^{8 c, 10 a, 16}$ we aimed at the development of a new general mechanostereoselective synthetic strategy to produce functionalized CD [3] rotaxanes as single isomers. Herein, we report a versatile five-component one-pot synthesis, that was applied to $\alpha-C D$ mono or bi-functionalized by Gd(III)-complexes (Figure 1) to obtain rotaxane based MRI contrast agents. In vitro relaxivity of these [3] rotaxanes and their use as biocompatible contrast agents for in vivo imaging in mouse models are also reported.

Scheme 1. Synthesis of head-to-head [3] rotaxanes.
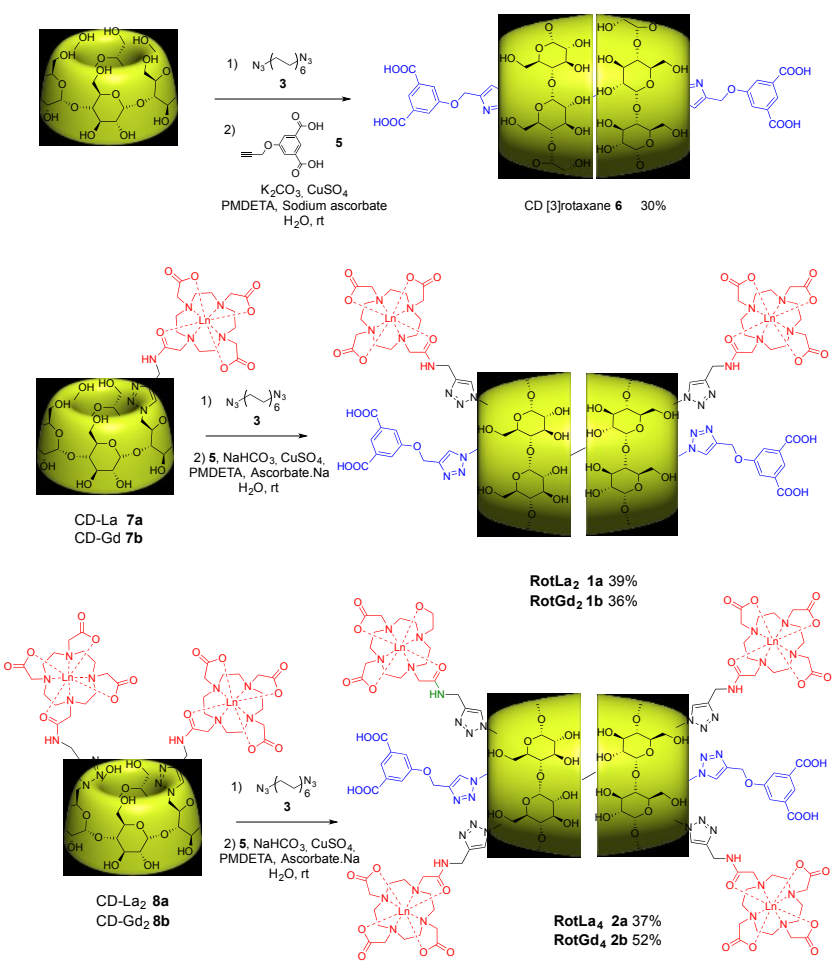

Rotaxanes were synthesized in a one-pot strategy using a hydrophobic $\mathrm{C}_{12}$ alkyl chain as thread and click chemistry for the stoppering reaction. The reaction conditions were optimized using native $\alpha-C D$ (Scheme 1). The diazidododecane axle 3 was, in a first step mixed with native $\alpha-C D$ in water to yield a pseudo-rotaxane by the hydrophobic effect. The formation of the inclusion complex can be observed by the appearance of turbidity in the reaction mixture. This turbidity is probably due to the formation of tubes of CD pseudorotaxanes and their aggregation via intermolecular hydrogen bonds as observed with other CD polyrotaxanes. ${ }^{17}$ In a second step, reactants for $\mathrm{CuAAC}$ and the stoppers were added to perform the end-capping reaction. The dicarboxylic acid $\mathbf{5}$ was chosen according to literature, ${ }^{16 a}$ as it is described to be large enough to prevent the dethreading of $\alpha-C D$. Moreover, the carboxylate groups enable the solubility of the rotaxane in water at physiological $\mathrm{pH}$, which is useful for potential in vivo studies.

The ${ }^{1} \mathrm{H}$ DOSY spectrum (Diffusion Ordered NMR) of the product 6 in DMSO showed the same diffusion coefficient for the protons of the CD, axle and stoppers (see Figure S1) indicating that they are part of the same supramolecular species. Moreover, the diffusion coefficient is lower than the one of each separate component, which is consistent with the larger molecular size of the assembly. Since DMSO is a solvent that prevents the formation of inclusion compounds with $\mathrm{CD},{ }^{13}$ the interlocked structure forms a stable rotaxane. The integration of the ${ }^{1} \mathrm{H}$ NMR spectrum and mass spectrometry (see Figure S5) showed the formation of a single symmetrical [3]rotaxane with two threaded CDs. 2D T-ROESY spectrum (Transverse Rotating-frame Overhauser Enhancement Spectroscopy, Figure 1) provided further evidence for the formation of the interlocked structure with correlation peaks between the central axle protons and inner pointing $\mathrm{CD}$ protons $\mathrm{H}^{3}$ and $\mathrm{H}^{5}$. Moreover, the correlation peak between $\mathrm{H}^{5}$ and protons $\mathrm{H}_{\mathrm{o}}, \mathrm{H}_{\mathrm{t}}$ and $\mathrm{H}_{\mathrm{s}}$ as well as $\mathrm{H}^{6}$ and $\mathrm{H}_{\mathrm{o}}$ indicates that the CDs have their primary rim pointing to the stoppers and their secondary rim pointing to each other, hence adopting the head-to-head orientational mechanoisomery. This orientation can be justified by the preferred establishment of hydrogen bonds between the complementary secondary rims, ${ }^{18}$ and is consistent with other [3] rotaxanes having an alkylene axle. ${ }^{13 \text {, }}$

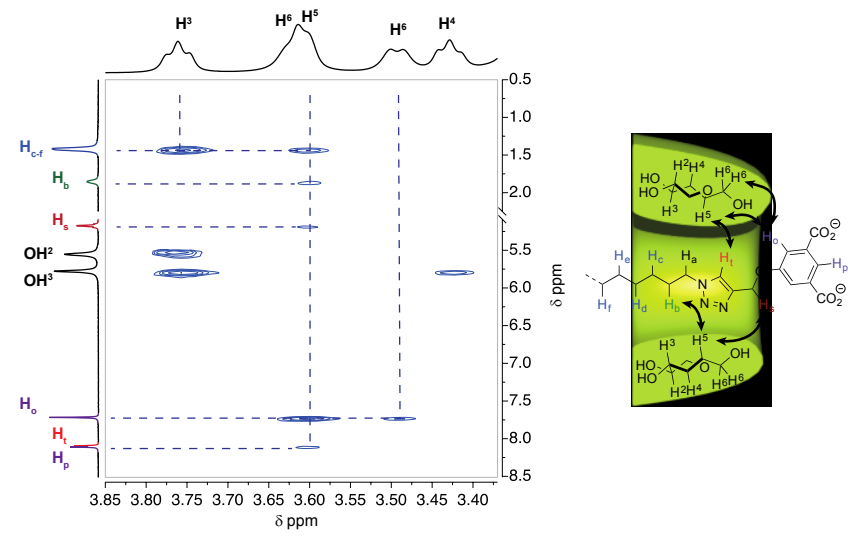

Figure 1. T-ROESY spectrum of CD [3] rotaxane 6 (600 MHz, DMSO-d 6 ).

$\alpha-C D$ was then selectively functionalized by gadolinium complex of 1,4,7,10-tetraazacyclododecane-1,4,7-triacetic acid monoamide (Gd-DO3A-MA) complexes to act as MRI contrast agent. The synthesis is based on a flexible approach using a regioselective deprotection of perbenzylated $\mathrm{CDs}^{19}$ and a Copper-catalyzed Azide-Alkyne Cycloaddition $(\mathrm{CuAAC})^{20}$ between protected mono ${ }^{21}$ and bis azido $\mathrm{CDs}^{22}$ and propargylfunctionalized DO3A-MA followed by deprotection as described in our previous publication. ${ }^{1} \mathrm{CDs}$ selectively mono- or di-functionalized on diametrically opposed A,D positions on the primary rim by Gd-DO3A-MA complexes were obtained. As MRI is not a very sensitive imaging technique, the difunctionalized CD $\mathbf{8}$ is particularly interesting in order to increase local Gd(III) concentration. ${ }^{23}$ Then, the same procedure was applied for the synthesis of the functionalized CD 
rotaxanes (Scheme 1) and the products were directly purified by size exclusion chromatography. The formation of the GdCD [3] rotaxanes RotGd $_{2}$ and RotGd $_{4}$ was confirmed by mass spectrometry (see Figure S6-7) with molecular ion peaks at $\mathrm{m} / \mathrm{z} 1292.05$ and 1706.14 respectively corresponding to [M$3 \mathrm{H}]^{3-}$ ions. The rotaxanes were obtained in $35-50 \%$ yield, which is suitable for a five-component one-pot reaction.

Lanthanum analogs (7a and 8a) were also synthesized to obtain further information on the interlocked structure by NMR studies. As observed with native CD, the same diffusion coefficient for the stoppers, functionalized CD and the axle in water was observed on the DOSY spectrum for RotLa 1 1a and RotLa4 2a (Figure S2-3). For both rotaxanes, correlation peaks between the inner cavity $\mathrm{CD} \mathrm{H}^{3}$ and $\mathrm{H}^{5}$ and central axle protons on the T-ROESY spectra (Figure S4) confirmed the interlocked structure. Moreover, correlation between $\mathrm{H}^{5}$ and triazolyl proton $\mathrm{H}_{\mathrm{t}}$ indicates that the primary rim of the functionalized $\mathrm{CD}$ is pointing to the stoppers. As observed with native $\mathrm{CD}$, this head-to-head configuration enables intramolecular hydrogen bonding between the two secondary rims and seems inherently favored, even though in this case it also avoids the steric hindrance between the substituents on the primary rims.

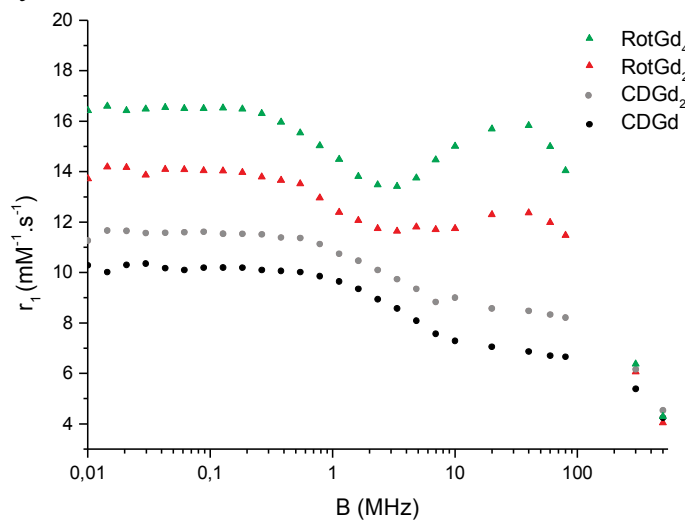

Figure 2. ${ }^{1} \mathrm{H}$ NMRD profiles of aqueous solution of CD-Gd, CDGd$_{2}, \operatorname{RotGd}_{2}$ and $\operatorname{RotGd}_{4}$ at $37^{\circ} \mathrm{C}$.

The effect of the supramolecular assembly on the longitudinal proton relaxivity of the $\mathrm{Gd}(\mathrm{III})$ complexes was then investigated by ${ }^{1} \mathrm{H}$ NMRD (Nuclear Magnetic Relaxation Dispersion) profiles by measuring $T_{1}$ at different magnetic fields. The profiles (Figure 2) were recorded in water at $37^{\circ} \mathrm{C}$ for the two rotaxanes (1) and $\mathbf{2 b}$ ) and compared to the corresponding CDs (7b and $\mathbf{8 b}$ ). The relaxivities per Gd are considerably higher for RotGd2 $\mathbf{1 b}$ and $\operatorname{RotGd}_{4} \quad \mathbf{2 b} \quad(12.30$ and $15.70 \mathrm{mM}^{-1} \cdot \mathrm{s}^{-1}$ at $20 \mathrm{MHz}$, respectively) than for the parent functionalized CDs (7.06 and $8.57 \mathrm{mM}^{-1} \cdot \mathrm{s}^{-1}$, respectively) or Gd-DOTA $^{24}\left(3.83 \mathrm{mM}^{-1} \cdot \mathrm{s}^{-1}\right)$ The relaxivity values are comparable to multimeric Gd-DOTA functionalized CD systems of similar size ([Gd-DOTA] $]_{7}-\beta-C D: 12.2 \mathrm{mM}^{-1} \cdot \mathrm{s}^{-1}$ at $60 \mathrm{MHz},{ }^{25}$ Gd-DO3A-HP- $\beta$-CD: $7.82 \mathrm{mM}^{-1} \cdot \mathrm{s}^{-1}$ at $60 \mathrm{MHz}{ }^{5}$ [GdDO3P] ${ }_{6.9}-\mathrm{F}_{0.1}-\beta-\mathrm{CD}: 21.6 \mathrm{mM}^{-1} \cdot \mathrm{s}^{-1}$ at $\left.20 \mathrm{MHz}^{26}\right)$. The NMRD profile shows an enhancement at medium field $(20-80 \mathrm{MHz})$ for the rotaxanes, which is not present for the functionalized CDs. This hump is characteristic of macromolecular contrast agents (such as polymers or liposomes) and it indicates that the interlocked architecture plays a crucial role in the rotational dynamics and subsequently in the relaxivity properties. The temperature dependence (Table S1) showing an increased relaxivity with increasing temperature is also an indication of the rigidity of the system. Indeed, it proves that the relaxivity is limited by the water exchange rate of the complex and not by its rotation. It is most notable that our small rotaxanes feature also those properties which were previously observed with polyrotaxanes (CD-Gd/polyammonium PR: 16.4 $\mathrm{mM}^{-1} \cdot \mathrm{s}^{-1} ;{ }^{1} \mathrm{CD}-\mathrm{Gd}_{2} /$ polyammonium PR: $19.6 \mathrm{mM}^{-1} \cdot \mathrm{s}^{-1} ;{ }^{1} \mathrm{Gd}-$ DO3A-HPCD/Pluronic PR: $22.8 \mathrm{mM}^{-1} \cdot \mathrm{s}^{-15}$ at $60 \mathrm{MHz}$ ). The [3] rotaxanes behave indeed as a typical macromolecular contrast agent with promising relaxation properties at relevant body temperature.

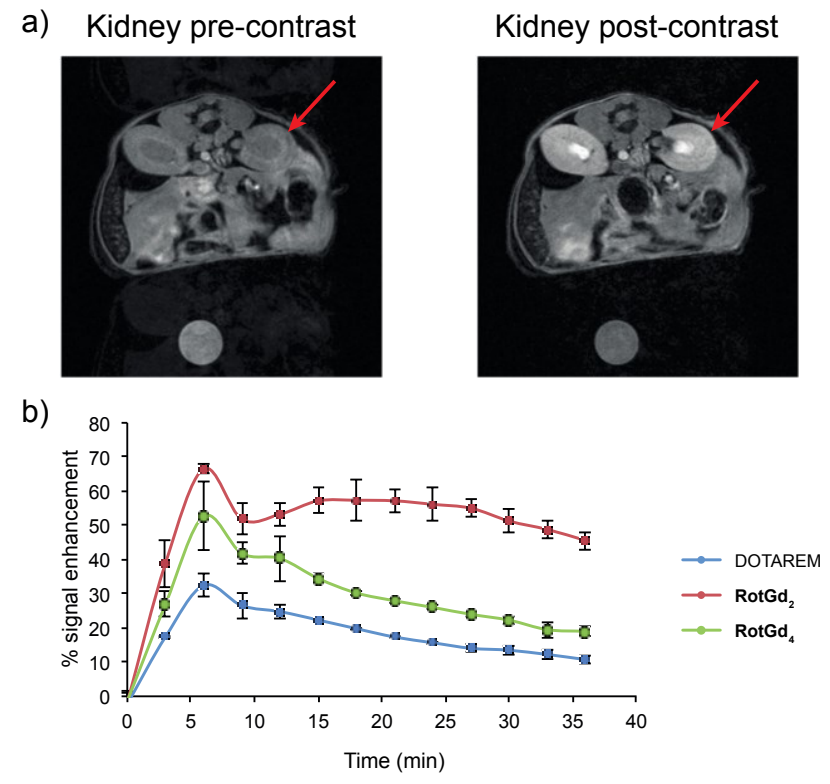

Figure 3. a) MRI cross-sections of the kidneys (red arrow) pre(left) and post-injection (right, $40 \mathrm{~min}$ ) of $\operatorname{RotGd}_{2}$ b) Dynamic MRI signal enhancement in renal cortex after CA injection.

The biodistribution of rotaxanes $\operatorname{RotGd}_{2}$ and $\operatorname{RotGd}_{4}$ was then studied in vivo on BALB/c mice using adapted dynamic MRI sequences at 7T. Several regions of interest (ROI) were monitored (liver and kidney) and the MRI intensities of the regions were plotted pre- and post injection of the contrast agent at $\mathrm{Gd}$ concentration of $50 \mu \mathrm{mol} \cdot \mathrm{kg}^{-1}$. Comparison with commercial Gd-DOTA as a reference was performed at the same concentration of Gd. Figure 3 shows MRI cross-sections where the kidney regions are highlighted as expected for the biodistribution of a molecular scaffold of a small size inferior to $5 \mathrm{~nm} \cdot{ }^{27}$ Comparison of the pre- and post-contrast images clearly reveals the higher brightness of the kidney caused by $\operatorname{RotGd}_{2}$. For further images of the liver with this CA, and of kidney and liver with RotGd 4 see SI (Figure S9-10). Contrast enhancements in both organs are expressed as percentage of enhancement compared to the pre-contrast image. The peaks of enhancement were observed at the same time, 6 minutes post-injection for all CA in the liver and the kidney followed by a phase of decay (Figure $3 \mathrm{~b}$ and S11). The absolute values at 21 min post injection are highest for $\operatorname{RotGd}_{2}(16 \%$ in the liver, $67 \%$ in the cortical region of the kidney), followed by those of RotGd 4 ( $9 \%$ and $28 \%$ respectively) and Gd-DOTA ( $6 \%$ and $17 \%$ respectively). After bloodstream circulation with a complementary transitory visualization through the vascular network in the liver, the CAs are excreted from the kidney cortex to the bladder. After $40 \mathrm{~min}$, the levels of RotGd 4 and Gd-DOTA came back to their pre-contrast values and to $10 \%$ signal enhancement for $\mathbf{R o t G d}_{\mathbf{2}}$ in the liver indicating a hepatic wash-out. However, a stronger retention in the cortical 
region of the kidney was observed with enhancement of $46 \%$ and $19 \%$ for $\operatorname{RotGd}_{2}$ and $\operatorname{RotGd}_{4}$, respectively (11\% for GdDOTA). Both rotaxanes behave similarly in the kidney glomerular and tubular clearance with slower elimination than the mononuclear complex Gd-DOTA. Due to the higher concentration of $\operatorname{RotGd}_{2}$ than that of $\operatorname{RotGd}_{\mathbf{4}}$ injected both for an identical final Gd amount, RotGd2 takes longer to be eliminated. This imaging study evidences that both rotaxanes display higher contrast enhancement than the commercial $\mathrm{CA}$ Gd-DOTA over the full observation period, without the typical liver accumulation observed for macromolecular agents. Thus, they improve the imaging properties without undesired liver uptake. The relatively long circulation time opens the perspective for vectorization towards other tissues than the kidney.

In summary, we have successfully developed a one-pot fivecomponent mechanostereoselective synthesis of head-to-head $\mathrm{CD}$ [3] rotaxanes leading to the first [3] rotaxanes with GdDO3A-MA functionalized CDs. These rotaxanes have shown their ability to significantly improve the relaxivity properties compared to parent CDs indicating the interest of this supramolecular approach for MRI applications. Indeed the behavior of [3] rotaxanes is already comparable with those of much larger macromolecular agents while keeping the advantages of small molecules in terms of synthesis and characterization at the molecular level. These rotaxanes are non-toxic, and their biodistribution could be investigated by MR imaging with high temporal resolution. Both rotaxanes exhibit higher contrast enhancement and retention than the commercial GdDOTA, with a particular improvement for RotGd2. In conclusion, rotaxanation is a viable approach to obtain contrast agents with improved efficiency, even when the rotaxanes are relatively small. This simple supramolecular approach has multiple advantages over conventional covalent strategies such as modularity and versatility. Indeed, each component is synthesized and characterized separately before the assembly, and can be exchanged at will by other components.

\section{ASSOCIATED CONTENT}

\section{Supporting Information}

Experimental procedures, compound characterization data, and NMR spectra. This material is available free of charge via the Internet at http://pubs.acs.org.

\section{AUTHOR INFORMATION}

\section{Corresponding Author}

* bernold.hasenknopf@upmc.fr; guillaume.vives@upmc.fr

\section{Author Contributions}

$\S$ These authors contributed equally.

\section{ACKNOWLEDGMENT}

We thank Agnès Pallier, Centre de Biophysique Moléculaire, CNRS UPR4301, Université d'Orléans, for performing ICP measurements on the $\mathrm{Gd}^{3+}$ containing samples. Financial support from UPMC (programme Emergence) and the LabEx MiChem programme under reference ANR-11-IDEX-0004-02 and from the Ligue contre le Cancer are acknowledged. We thank also the Institut Weizmann Français for the postdoctoral fellowship to G. Ramniceanu and the IDEX Programme interdisciplinaire, Université Paris Descartes SINON and Université Paris Descartes for the MRI equipment.

\section{REFERENCES}

(1) Fredy, J. W.; Scelle, J.; Guenet, A.; Morel, E.; Adam de Beaumais, S.; Ménand, M.; Marvaud, V.; Bonnet, C. S.; Tóth, E.; Sollogoub, M.; Vives, G.; Hasenknopf, B. Chem. Eur. J. 2014, 20, 10915-10920.

(2) Neal, E. A.; Goldup, S. M. Chem. Commun. 2014, 50, 5128-5142.

(3) (a) Sauvage, J.-P.; Dietrich-Buchecker, C. Molecular Catenanes, Rotaxanes and Knots; Wiley-VCH Verlag GmbH, 1999; (b) Amabilino, D. B.; Perez-Garcia, L. Chem. Soc. Rev. 2009, 38 , 1562-1571; (c) Forgan, R. S.; Sauvage, J.-P.; Stoddart, J. F. Chem. Rev. 2011, 111, 5434-5464; (d) van Dongen, S. F. M.; Cantekin, S.; Elemans, J. A. A. W.; Rowan, A. E.; Nolte, R. J. M. Chem. Soc. Rev. 2014, 43, 99-122.

(4) (a) Khan, A. R.; Forgo, P.; Stine, K. J.; D'Souza, V. T. Chem Rev. 1998, 98, 1977-1996; (b) Sollogoub, M. Synlett 2013, 24, 2629-2640; (c) Sollogoub, M. Eur. J. Org. Chem. 2009, 2009, 1295-1303; (d) Wang, B.; Zaborova, E.; Guieu, S.; Petrillo, M.; Guitet, M.; Blériot, Y.; Ménand, M.; Zhang, Y.; Sollogoub, M. Nat Commun 2014, 5, 5354.

(5) Zhou, Z.; Mondjinou, Y.; Hyun, S.-H.; Kulkarni, A.; Lu, Z.-R.; Thompson, D. H. ACS Appl. Mater. Interfaces 2015, 7, 2227222276 .

(6) (a) Wenz, G.; Han, B.-H.; Müller, A. Chem. Rev. 2006, 106, 782817; (b) Harada, A.; Hashidzume, A.; Yamaguchi, H.; Takashima, Y. Chem. Rev. 2009, 109, 5974-6023.

(7) Ogino, H. J. Am. Chem. Soc. 1981, 103, 1303-1304.

(8) (a) Wang, Z.-B.; Takashima, Y.; Yamaguchi, H.; Harada, A. Org. Lett. 2011, 13, 4356-4359; (b) Wenz, G.; Von der Bey, E.; Schmidt, L. Angew. Chem., Int. Ed. 1992, 31, 783-5; (c) Chwalek, M.; Auzely, R.; Fort, S. Org. Biomol. Chem. 2009, 7, 1680-1688; (d) Mondjinou, Y. A.; Hyun, S. H.; Xiong, M.; Collins, C. J.; Thong, P. L.; Thompson, D. H. ACS Appl Mater Interfaces 2015 , 7, 23831-6.

(9) Wenz, G.; Keller, B. Angew. Chem., Int. Ed. 1992, 31, 197-199.

(10)(a) Hänni, K. D.; Leigh, D. A. Chem. Soc. Rev. 2010, 39, $1240-$ 1251; (b) Beves, J. E.; Blight, B. A.; Campbell, C. J.; Leigh, D. A.; McBurney, R. T. Angew. Chem., Int. Ed. 2011, 50, 92609327; (c) Xue, M.; Yang, Y.; Chi, X.; Yan, X.; Huang, F. Chem. Rev. 2015, 115, 7398-7501.

(11)(a) Crowley, J. D.; Goldup, S. M.; Lee, A.-L.; Leigh, D. A.; McBurney, R. T. Chem. Soc. Rev. 2009, 38, 1530-1541; (b) Movsisyan, L. D.; Franz, M.; Hampel, F.; Thompson, A. L.; Tykwinski, R. R.; Anderson, H. L. J. Am. Chem. Soc. 2016, 138, 1366-76.

(12)Craig, M. R.; Claridge, T. D. W.; Hutchings, M. G.; Anderson, H. L. Chem. Commun. 1999, 1537-1538.

(13)(a) Akae, Y.; Okamura, H.; Koyama, Y.; Arai, T.; Takata, T. Org Lett. 2012, 14, 2226-2229; (b) Akae, Y.; Koyama, Y.; Kuwata, S.; Takata, T. Chem. - Eur. J. 2014, 20, 17132-17136; (c) Akae, Y.; Koyama, Y.; Sogawa, H.; Hayashi, Y.; Kawauchi, S.; Kuwata, S.; Takata, T. Chem. Eur. J. 2016, 22, 5335-5341.

(14)Daniell, H. W.; Klotz, E. J. F.; Odell, B.; Claridge, T. D. W.; Anderson, H. L. Angew. Chem., Int. Ed. 2007, 46, 6845-6848.

(15)Qu, D. H.; Wang, Q. C.; Ma, X.; Tian, H. Chem. Eur. J. 2005, 11, 5929-5937.

(16)(a) Zhao, Y.-L.; Dichtel, W. R.; Trabolsi, A.; Saha, S.; Aprahamian, I.; Stoddart, J. F. J. Am. Chem. Soc. 2008, 130, 11294-11296; (b) Loethen, S.; Ooya, T.; Choi, H. S.; Yui, N.; Thompson, D. H. Biomacromolecules 2006, 7, 2501-6; (c) Ooya, T.; Inoue, D.; Choi, H. S.; Kobayashi, Y.; Loethen, S.; Thompson, D. H.; Ko, Y. H.; Kim, K.; Yui, N. Org Lett 2006, 8, 3159-62.

(17)Harata, K. Chem. Rev. 1998, 98, 1803-1828.

(18)Kamitori, S.; Matsuzaka, O.; Kondo, S.; Muraoka, S.; Okuyama, K.; Noguchi, K.; Okada, M.; Harada, A. Macromolecules 2000, $33,1500-1502$

(19)Lecourt, T.; Herault, A.; Pearce, A. J.; Sollogoub, M.; Sinaÿ, P. Chem. Eur. J. 2004, 10, 2960-2971.

(20)(a) Tornøe, C. W.; Christensen, C.; Meldal, M. J. Org. Chem. 2002, 67, 3057-3064; (b) Rostovtsev, V. V.; Green, L. G.; Fokin, 
V. V.; Sharpless, K. B. Angew. Chem., Int. Ed. 2002, 41, 25962599.

(21)Guieu, S.; Sollogoub, M. Angew. Chem., Int. Ed. 2008, 47, 70607063.

(22)(a) Deunf, E.; Zaborova, E.; Guieu, S.; Blériot, Y.; Verpeaux, J.N.; Buriez, O.; Sollogoub, M.; Amatore, C. Eur. J. Inorg. Chem. 2010, 2010, 4720-4727; (b) Ménand, M.; Adam de Beaumais, S.; Chamoreau, L.-M.; Derat, E.; Blanchard, S.; Zhang, Y.; Bouteiller, L.; Sollogoub, M. Angew. Chem., Int. Ed. 2014, 53, 7238-7242.

(23)The Chemistry of Contrast Agents in Medical Magnetic Resonance Imaging; 2nd ed.; Merbach, A.; Helm, L.; Toth, E., Eds.; John Wiley \& Sons, Ltd, 2013.
(24)Powell, D. H.; Dhubhghaill, O. M. N.; Pubanz, D.; Helm, L.; Lebedev, Y. S.; Schlaepfer, W.; Merbach, A. E. J. Am. Chem. Soc. 1996, 118, 9333-9346.

(25)Song, Y.; Kohlmeir, E. K.; Meade, T. J. J. Am. Chem. Soc. 2008 , 130, 6662-6663.

(26)Kotková, Z.; Kotek, J.; Jirák, D.; Jendelová, P.; Herynek, V.; Berková, Z.; Hermann, P.; Lukeš, I. Chem. Eur. J. 2010, 16, 10094-10102.

(27)Choi, H. S.; Liu, W.; Misra, P.; Tanaka, E.; Zimmer, J. P.; Itty Ipe, B.; Bawendi, M. G.; Frangioni, J. V. Nat Biotechnol 2007, $25,1165-70$. 